\title{
TEORÍA DEL DERECHO
}

La expresión "teoría del derecho" es de vieja data, pero su utilización para una disciplina especial de la ciencia jurídica no tiene más de cuatro décadas. Sin embargo, la materia teoría del derecho tampoco es tan nueva, pues lo que en el siglo XIX y comienzos del XX se ofrecía con la etiqueta de "doctrina general del derecho" no es en verdad completamente lo mismo, pero sí bastante semejante a la actual teoría del derecho.

Arthur Kaufmann, Filosofía del derecho (1997), p. 49

La teoría del derecho contemporánea, concebida fundamentalmente como una indagación acerca de la práctica jurídica —y en especial acerca de la adjudicación o aplicación del derecho por parte de los jueces en casos concretos-, gira alrededor de dos preguntas inquietantes y siempre recurrentes. De una parte, ilos sistemas jurídicos son internamente coherentes o incoherentes? Y de otra, ilos jueces son aplicadores neutrales de normas jurídicas o creadores de derecho inspirados en razones políticas y morales? Estas dos preguntas, que han sido enunciadas aquí en su forma descriptiva, aparecen en los debates teóricos acompañadas generalmente de sus equivalentes prescriptivos: icómo deben ser los ordenamientos jurídicos? Y icómo deben aplicar los jueces el derecho?

\author{
César Rodríguez, "Estudio preliminar", \\ en Duncan Kennedy, \\ Libertad y restricción en la decisión judicial, p.19
}

¿Por qué Carl Schmitt?

Bernhard Schlink

Gustav Radbruch: ¿Constituye hoy el positivismo una condición del pluralismo liberal?

Alejandro Aponte

El derecho como modelo para las ciencias naturales Vittorio Villa 



\title{
¿Por qué Carl Schmitt?*
}

\author{
Bernhard Schlink
}

\begin{abstract}
In juridical German culture, Carl Schmitt achieved more noted prestige than other contemporary theorists of German law of that time. The reason for this is hereby examined: The contribution of Schmitt's thought to interpret and apply Fundamental Law? The contributions of his political theory? The answer to these two questions is negative. His fame derives from the place that myth granted him regarding positivism and the direction of law during the Nazi regimen. It is caused by the difficulty to integrate juridical trends of the Third Reich with the history of legal German culture. An attempt to achieve this was to resort to an erroneous interpretation ad hoc of Schmitt's personality.
\end{abstract}

¿Por qué Carl Schmitt? ¿Por qué, de todas las personas, Carl Schmitt juega un rol tan importante en la cultura jurídica de la República Federal de Alemania? ¿Por qué no Smend, Heller, Kelsen, Anschütz, o Thoma? ¿Acaso las contribuciones de Schmitt al derecho constitucional son más válidas que las de sus contemporáneos; acaso ayudan más a interpretar y aplicar la constitución actual, la Ley Fundamental (Grundgesetz)? ¿Son más profundas sus teorías políticas? ¿Contribuyen más a promover el análisis de los desarrollos políticos actuales?

El análisis que hizo Schmitt de la Constitución de Weimar ha influido en el análisis de la Ley Fundamental de cuatro maneras principales. Primero, con respecto a las reformas constitucionales. El artículo 76 de la Constitución de Weimar fue redactado y en general interpretado de tal manera que, dada una

\footnotetext{
"Agradecemos a Bernhard Schlink la amable autorización para publicar su ponencia Why Carl Schmitt? presentada en la conferencia sobre "Carl Schmitt y el desafío a la teoría democrática," organizada por la New School for Social Research, en 1990.
} 
mayoría suficiente, cualquier reforma a la Constitución era posible. 'De hecho, una reforma podía alterar la identidad misma de la Constitución, convirtiendo una república en una monarquía, un Estado federal en uno centralizado, un Estado con derechos fundamentales en uno sin esos derechos, etc. Schmitt se opuso a esta flexibilidad. ${ }^{2}$ Él afirmó que el poder de cambiar la Constitución se desprende de la Constitución misma, y por lo tanto debe atenerse a sus principios. Según Schmitt, cambiar la identidad de la Constitución ya no corresponde a una mera reforma constitucional; anula la Constitución en sí. Por lo tanto, consideró que no debía permitirse una discrecionalidad ilimitada para reformar la Constitución. La Ley Fundamental, en el inciso 3o de su artículo 79, anuncia hoy de manera explícita que es inaceptable una reforma constitucional que afecte el carácter federal del Estado o ciertos principios de la organización o de la autoridad estatales. Todavía se debate hasta qué punto influyeron las ideas de Schmitt sobre el artículo 76 de la Constitución de Weimar en la formulación del artículo 79, inciso 3o, de la Ley Fundamental. ${ }^{3}$ Para algunos, sin embargo, el hecho de que el artículo 79 se haya redactado según la crítica que le formuló Schmitt al artículo 76 constituye una deuda explícita a la crítica de Schmitt. ${ }^{4}$

En segundo lugar, está el voto de no confianza. De acuerdo con el artículo 54 de la Constitución de Weimar, se podía retirar al Canciller y a los Ministros del Reich en caso de que se presentara una pérdida explícita de la confianza, o, en otras palabras, un voto de no confianza. La mayoría de las personas

\footnotetext{
${ }^{1}$ Ver G. Anschütz, Die Verfassung des Deutschen Reichs vom 11. August 1919; Kommentar Art. 76 comentario 3 (14 Ed. 1933); Thoma, "Grundbegriffe und Grundsätze," en 2 Handbuch des Deutschen Staatsrechts (G. Anschütz y R. Thoma, 1932) [desde ahora en adelante, Handbuch], 153ss.

${ }^{2}$ Carl Schmitt, Verfassungslehre (1928).

${ }^{3}$ Las publicaciones sobre los orígenes del Grundgesetz no se refieren a Schmitt. Ver van Doeming, Füsslein, y Matz, "Entstehungsgeschichte der Artikel des Grundgesetzes," en I Jahrbuch des Öffentlichen Rechts (1951), 584 [desde ahora en adelante, Jahrbuch]; "Bericht über den Verfassungskonvent auf Herrenchiemsee vom 10-23 August, 1948” (Bayerische Staatskanzlei, 1948), 48.

${ }^{4}$ Dürig, "Zurück zum klassischen Enteignungsbegriff," en Juristenzeitung 7 (1954); H. P. Ipsen, Über das Grundgesetz (1950), 28; T. Maunz y G. Dürig, Grundgesetz (comentario) Art. 79 comment 24 (1960); Mussgnug, "Carl Schmitts verfassungsrechtliches Werk und sein Fortwirken im Staatsrecht der Bundesrepublik Deutschland," en Complexio Oppositorum: Über Carl Schmitt (H. Quaritsch, 1988), 519 [desde ahora en adelante, Complexio Oppositorum]; Schneider, "Über Einzelfallgesetze," en Festschrift für Carl Schmitt zum 70. Geburtstag (H. Barion, E. Forsthoff, y W. Weber, 1959), 170.
} 
entendía que para efectos del artículo 54 no importaban los motivos o las circunstancias del voto. ${ }^{5}$ No obstante, Schmitt, como Fraenkel, distinguía entre votos de no confianza negativos y positivos. ${ }^{7} \mathrm{Su}$ argumento consistía en que sólo se debía permitir un voto positivo, en el sentido de que sólo la confianza puesta en un nuevo régimen podía corregir la falta de confianza en el régimen anterior. Un voto negativo, u obstruccionista (entendido como un voto adelantado por fuerzas diversas que, a pesar de unirse para censurar el viejo régimen, no podían ponerse de acuerdo en un nuevo régimen), no podía, para Schmitt, obligar al gobierno a renunciar. Aquí, de nuevo, la Ley Fundamental comparte la crítica de Schmitt. El artículo 67 sólo permite un voto de confianza positivo (hoy conocido como constructivo), a través del cual el Parlamento (Bundestag) manifiesta su falta de confianza en el canciller anterior eligiendo un nuevo canciller. De nuevo, se debate qué tan conscientes de la crítica de Schmitt fueron los redactores de la Ley Fundamental al crear el artículo 67. En cualquier caso, a algunos les gusta decir que fue incorporada la posición de Schmitt.

La tercera forma en la que se considera que Schmitt es influyente es en el área de los derechos básicos. En su sección de derechos básicos, la Constitución de Weimar no sólo incluía las garantías clásicas de la igualdad, la libertad, y la propiedad, sino, además, abundantes afirmaciones programáticas sobre la educación, la seguridad social, y los roles que desempeñan la empresa y el trabajo en la sociedad. Al aparecer junto a los derechos básicos clásicos, por lo general estos puntos programáticos fueron marginados como meros deseos y como promesas opcionales. ${ }^{9}$ Schmitt no fue el único crítico en este punto. ${ }^{10}$

${ }^{5}$ Ver G. Anschütz, Verfassung, en Art. 54 comentario 6; Thoma, "Die rechtliche Ordnung des parlamentarischen Regierungssystems," en 1 Handbuch, 511.

${ }^{6}$ Schmitt, Verfassungslehre, 344ss.

${ }^{7}$ Fraenkel, "Verfassungsreform und Sozialdemokratie," en Zur Soziologie der Klassenjustiz und Aufsätze zur Verfassungskrise 1931-1932 (E. Fraenkel, 1968), 97.

${ }^{8}$ Mussgnug, Carl Schmitt, 526.

${ }^{9}$ Ver G. Anschütz, Verfassung, en la observación introductoria al Art. 109, comentario 6; W. Eisenlohr, Die juristische Bedeutung programmatischer Bestimmungen in der Reichsverfassung (1932) (disertación), 45; Thoma, "Die juristische Bedeutung der grundrechtlichen Sätze der Reichsverfassung im allgemeinen," en 1 Die Grundrechte und Grundpflichten der Reichsverfassung (H. C. Nipperdey, 1929), 3ss.

${ }^{10}$ Schmitt, Verfassungslehre, 162; "Inhalt und Bedeutung des zweiten Hauptteils der Reichsverfassung," en 1 Handbuch 598-599, 603ss [desde ahora en adelante, "Inhalt und Bedeutung"]. 
La decisión de incluir sólo los derechos básicos en la Ley Fundamental, para prevenir que se diluyeran, se les puede atribuir a muchos otros pensadores distintos a Schmitt. ${ }^{11}$ De todas maneras, su influencia es destacable. Schmitt forjó términos y trazó distinciones en su crítica a las afirmaciones programáticas de la Constitución de Weimar que siguen siendo importantes en el análisis de los derechos básicos. Por ejemplo, Schmitt clasificó las "garantías institucionales" como una categoría propia, distinta tanto de los derechos básicos clásicos como de las afirmaciones programáticas. ${ }^{12}$ Las garantías institucionales son esas garantías de fundamento constitucional que protegen ciertas instituciones privadas y públicas, tales como el matrimonio, la familia, la propiedad, la función pública, y el gobierno local. ${ }^{13}$ La perspectiva de Schmitt contribuyó al hecho de que hoy en día todos los derechos básicos comprenden tanto los derechos individuales como la responsabilidad del Estado de crear un ambiente que proteja esos derechos. Como tales, los procedimientos institucionales para promover y asegurar los derechos básicos son necesarios aún allí donde las garantías institucionales, en el sentido de Schmitt, no se encuentran. ${ }^{14}$

También es importante la forma en que Schmitt se plantea las garantías clásicas de la libertad. Según Schmitt, estos derechos deben entenderse siguiendo un principio distributivo. La distribución será de tal naturaleza que el ámbito de la libertad individual debe ser ilimitado, mientras las posibilidades de intervención estatal deben ser limitadas, medibles, y controlables. ${ }^{15}$ Esto se ajusta a una manera profundamente moderna de entender los derechos básicos, según la cual no es necesario justificar las reclamaciones individuales de libertad sino, en cambio, todo intento del Estado de limitar la libertad. En caso de que surja un conflicto, la carga de la justificación y la argumentación recae no sobre el individuo sino sobre el Estado.

\footnotetext{
${ }^{11}$ Ver E. Denninger, 1 Alternativkommentar zum Grundgesetz, 58ss, 94; I. von Münch, GrundgesetzKommentar Arts. 1-19 comentario 18 (3 Ed., 1985).

${ }^{12}$ Schmitt, Verfassungslehre, 162; Schmitt, "Inhalt und Bedeutung," 595-596.

${ }^{13}$ T. Maunz \& Dürig, "Zuruck," en el Art. 1 comentario 79 (1958); O. Kimminich, Kommentar zum Bonner Grundgesetz Art. 14 comentarios 26, 28 (1960); H. von Mangoldt, Das Bonner Grundgesetz Art. 14 comentario 2 (1953).

${ }^{14}$ BverfGE 7, 198/205; 35, 79/114; 39, 1/41; A Bleckmann, Staatsrecht II: Die Grundrechte (3 Ed., 1989), 253; E. Denninger, I Alternativkommentar, en la Introducción antes de Art. 1 comentario, 29-30; K. Hesse, Grundzüge des Verfassungsrechts der Bundesrepublik Deutschland (16 Ed., 1988), 112ss; I. v. Münch, Grundgesetz-Kommentar, en Arts. 1-19 comentario 22.

${ }^{15}$ Schmitt, Verfassungslehre, 166ss; Schmitt, "Inhalt und Bedeutung," 591-592.

${ }^{16}$ R. Alexy, Theorie der Grundrechte (1986), 516; Böckenförde, "Grundrechtstheorie und Grun drechtsinterpretation," en Neue Juristische Wochenschrift (1974), 1531; A. Podlech, Gehalt und Funktionen des allgemeinen verfassungsrechtlichen Gleichheitssatzes (1971), 87; B. Schlink, Abwägung im Verfassungsrecht (1976), 192ss.
} 
La cuarta área de influencia reúne los aportes que le hizo Schmitt al campo de los conceptos y la terminología, más que a las construcciones teóricas. Por ejemplo, Schmitt definió el derecho legislado como abstracto y general. ${ }^{17}$ Esto nunca fue obligatorio bajo la Ley Fundamental, pero por mucho tiempo funcionó como una directriz. Las leyes que regulaban casos únicos eran consideradas excepciones que exigían justificación especial. ${ }^{18}$ En las discusiones sobre los estados de emergencia, la distinción terminológica de Schmitt entre dictaduras provisionalmente habilitadas y dictaduras auto-proclamadas ("kommissarische und souveräne Diktatur") ${ }^{19}$ todavía se escucha. En los debates sobre plebiscitos y referendos, se recuerda la manera en que él distinguía entre democracia directa e indirecta. ${ }^{20}$ Él es la fuente del compromiso verbal dilatorio ("dilatorischer Formelkompromi $\beta$ "), un compromiso que detiene la controversia por un tiempo, a través de una fórmula legal o constitucional. Sin embargo, no resuelve el conflicto, creando en cambio una ilusión de solución que de hecho les permite a los adversarios mantener su apariencia y sólo luego levantar la daga. ${ }^{21} \mathrm{Y}$ al referirse al tribunal constitucional federal (Bundesverfassungsgericht) como el protector de la constitución, ${ }^{22}$ se hace con la conciencia de que Schmitt originalmente usó la frase para describir al presidente del Reich. ${ }^{23}$

En general, estos puntos sugieren que el análisis de Schmitt del derecho constitucional fue influyente en grado impresionante. Pero sería engañoso describirlo como un pensador cuya influencia es inigualada. En la generación de Schmitt, y en la generación que lo precedió, una larga serie de constitucionalistas aportaron análisis que no fueron menos importantes para interpretar y aplicar la Ley Fundamental. Por ejemplo, le debemos a Laband el concepto del Estado como una persona jurídica; ${ }^{24}$ a Jellinek el sistema de derechos indivi-

${ }^{17}$ Forsthoff, "Über Maßnahmegesetze," en Gedächtnisschrift für Walter Jellinkek (O. Bachof, Ed., 1955), 22; Menger \& Werhahn, "Das Gesetz als Norm und Maßnahme," en 15 Veröffentlichungen der Vereinigung der Deutschen Staatsrechtslehrer (1957), 3, 35; Schneider, "Über Einzelfallgesetze," 159.

${ }^{18}$ Schmitt, Verfassungslehre, 151ss.

${ }^{19}$ Schmitt, Die Diktatur (2 Ed., 1958).

${ }^{20}$ Schmitt, Verfassungslehre, 204ss.

${ }^{21}$ Ibid., 31ss.

22 "Bundesverfassungsgericht: Denkschrift," en 6 Jahrbuch, ver nota 3, 144-145; Roellecke, "Aufgabe und Stellung des Bundesverfassungsgerichts in der Gerichtsbarkeit," en 2 Handbuch des Staatsrechts (J. Isensee y P. Kirchhof, 1987), 685; K. Stern, 2 Staatsrecht der Bundesrepublik Deutschland (1980), 333 [desde ahora en adelante, Staatsrecht].

${ }^{23}$ Schmitt, Der Hüter der Verfassung (1931).

${ }^{24}$ P. Laband, I Das Staatsrecht des Deutschen Reiches (5 Ed., 1914), 55ss. 
duales y subjetivos, y la responsabilidad objetiva del Estado por promoverlos; ${ }^{25}$ a Anschütz y Otto Mayer la premisa de que las infracciones de los derechos básicos a manos del Estado deben fundamentarse en disposiciones legales expresas; ${ }^{26}$ y a Smend su novedosa forma de entender la libertad de expresión y sus limitaciones. ${ }^{27}$ ¿Por qué Carl Schmitt? La pregunta de por qué juega un rol tan importante en la cultura jurídica de la República Federal de Alemania no se responde con la sola indicación de sus aportes al derecho constitucional.

\section{II}

¿Encontramos, en cambio, la respuesta en las teorías políticas de Schmitt? ¿No es más valioso hoy como un teórico de la política que como un académico del derecho constitucional?

De hecho, los términos y frases con los que asociamos a Schmitt se derivan de sus teorías políticas. Pensemos en las conocidas expresiones "romanticismo político" ${ }^{28}$ y "teología política," "legitimidad frente a legalidad,"30 "decisión frente a norma," "' "estructura social y orden frente a norma y decisión. ${ }^{32} \mathrm{Y}$ piense en frases pegajosas como "el soberano es aquel que decide el estado de excepción,"33 "toda la terminología constitucional es intrínsecamente teológica, "34 "la política se basa en la distinción entre amigo y enemigo," "el "Estado se basa en la política,"36 "con una constitución una nación decide cómo existirá

${ }^{25}$ G. Jellinek, System der subjektiven öffentlichen Rechte (2 Ed., 1905).

${ }^{26}$ G. Anschütz, Die Verfassungsurkunde für den preußischen Staat vom 31. Januar 1850 (comentario) Art. 3 comentario 3 (1912); O. Mayer, I Deutsches Verwaltungsrecht (2 Ed., 1914), 75; Mayer, "Besprechung Adolf Arndt: Das selbständige Verordnungsrecht," en 18 Archiv für Öffentliches Recht (1903), 101.

${ }^{27}$ Smend, "Das Recht der freien Meinungsäußerung," en 4 Veröffentlichungen der Vereinigung der Deutschen Staatsrechtslehrer (1928), 44.

${ }^{28}$ C. Schmitt, Politische Romantik (2 Ed., 1925) (traducción al inglés: G. Oakes, Political Romanticism [1986]).

${ }^{29}$ C. Schmitt, Politische Theologie (1922) (traducción al inglés: G. Schwab, Political Theology [1985]) [desde ahora en adelante, Political Theology].

${ }^{30}$ C. Schmitt, Legalität und Legitimität (1932).

${ }^{31}$ C. Schmitt, Der Begriff des Politischen (1932) (traducción al inglés: G. Schwab, The Concept of the Political [1976]) [desde ahora en adelante, The Concept of the Political].

${ }^{32}$ C. Schmitt, Über die drei Arten des wissenschaftichen Denkens (1934).

${ }^{33}$ Esta es la frase con la que empieza Political Theology.

${ }^{34}$ Ibid., 49.

${ }^{35}$ Con esta frase empieza The Concept of the Political.

${ }^{36}$ Ibid., 20. 
políticamente. ${ }^{37}$ Estas son las expresiones y frases pegajosas por las cuales se recuerda a Schmitt, y todas pertenecen a su teoría política. La especialidad de Schmitt, como un teórico de la política, deberá recordarse a través de lemas. Y que no pensemos que ellos se circunscriben al discurso académico. Por ejemplo, el pensamiento en términos de amigo y enemigo, y la toma de decisiones basada en esa distinción, se han convertido en lugares comunes de las discusiones políticas en general. ${ }^{38}$

Si nos detenemos en las teorías que encontramos detrás de los lemas de Schmitt, no corre una mejor suerte que con sus aportes constitucionales. De nuevo, su influencia es impresionante, pero una larga serie de teóricos de la política de la misma generación de Schmitt, y de la anterior, no son menos importantes o influyentes hoy. Pensemos en la influencia, por ejemplo, del concepto de Jellinek del Estado como una unión de tres elementos (poder, población, y territorio), ${ }^{39}$ al igual que en su reconocimiento del impacto normativo de los hechos ("normative Kraft des Faktischen"); ${ }^{40}$ en la noción de Kelsen de que el Estado y el derecho son iguales; ${ }^{41}$ en el intento de Heller de combinar una perspectiva legal con una sociológica al tratar el Estado; ${ }^{42}$ en la forma en que Thoma entendió la democracia como algo necesariamente liberal y el liberalismo como algo necesariamente democrático. ${ }^{43}$ La teoría de Schmitt sobre el decisionismo tiene su equivalente en la teoría de Smend sobre la integración. ${ }^{44}$ Sobre la soberanía y sobre la semejanza entre la terminología constitucional y la teológica, Kelsen no tuvo menos para decir que Schmitt. ${ }^{45}$

\footnotetext{
${ }^{37}$ Schmitt, Verfassungslehre, 20ss.

${ }^{38}$ Con respecto a la discusión sobre la admisión de los llamados "radicales" como funcionarios públicos, ver, por ejemplo, Koschnik, "Warum, Praxis und Folgen des Extremistenbeschlusses seine Abschaffung nötig machen," en Der Abschied vom Extremistenbeschluß (H. Koschnik, 1979), 34; Kriele, "Die Gewähr der Verfassungstreue," Frankfurter Allgemeine Zeitung (Oct. 25, 1978), 10; ver también I. Ebsen, Das Bundesverfassungsgericht als Element gesellschaftlicher Selbstregulierung (1985), 337 (invocando el sentido general de "Feinderklärungen" contra los comunitas y fascistas en la República Federal de Alemania). El "decisionismo" se usa hasta el debate político-cultural. Ver Hoffman, "Kultupolitik in der Defensive," Frankfurter Allgemeine Zeitung (Feb. 14, 1990), 36.

${ }^{39}$ G. Jellinek, Allgemeine Staatslehre (3 Ed., 1914), 182-183, 394ss.

${ }^{40}$ Ibid., 337 ss.

${ }^{41}$ H. Kelsen, Allgemeine Staatslehre (1925), 16.

${ }^{42}$ H. Heller, Staatslehre (G. Niemeyer, 1934), 228.

${ }^{43}$ R. Thoma, Der Begriff der modernen Demokratie in seinem Verhältnis zum Staatsbegriff (1923), 40ss.

${ }^{44}$ R. Smend, Verfassung und Verfassungsrecht (1928).

${ }^{45}$ Kelsen, "Gott und Staat," en 11 Logos (1922-1923), 261.
} 
Sobre el romanticismo político, como también sobre el parlamentarismo moderno, Schmitt pudo haber hablado de manera brillante, pero ni siquiera intentó hacer una crítica o un análisis justos. En cambio, fue abiertamente polémico. ${ }^{46}$ Su definición de la política como algo que se basa en la distinción entre amigo y enemigo ha demostrado ser menos que útil, y el llamado que la impulsa (un llamado a la burguesía alemana de la década de los veinte para que fuera decisiva políticamente) es claramente anticuado. ${ }^{47}$ Su teoría de la sociedad sistemática y estructurada, su "konkretes Ordnungs - und Gestaltungsdenken" es una variante, con matices nazis, del pensamiento jurídico institucional. La idea de que la época de los Estados-naciones ha sido reemplazada por una época de super-regiones y hemisferios, de que esta época culmina en el contraste entre Oriente y Occidente y de que se vincula al contraste elemental entre tierra y $\mathrm{mar}^{48}$ - estas consideraciones, que se derivaron de la Segunda Guerra Mundial y de la Guerra Fría, son todas un producto del espíritu de la época y, por ahora, han demostrado estar limitadas a los confines de su época.

Ésta no es una crítica al hombre que entendía todos los términos como políticos y polémicos, y que siempre estaba luchando: hasta 1945 contra Weimar, Ginebra, y Versalles; después de 1945, contra sus opositores. No obstante, todo esto muestra que la respuesta a la pregunta contenida en el título no se encontrará en el poder analítico y sistemático de sus teorías. Esto se volvió bastante claro durante una conferencia sobre Schmitt que se realizó en $1986,{ }^{49}$ la más grande conferencia sobre Schmitt hasta la fecha, en la que participaron sus seguidores y en la que no faltaron algunos de sus críticos. En

${ }^{46}$ Con respecto a la crítica a la obra de Schmitt sobre el romanticismo político, ver V. Neumann, Der Staat im Bürgerkrieg: Kontinuität und Wandlung in der politischen Theorie Carl Schmitts (1980), 45. Con respecto a críticas a la manera en que Schmitt critica el parlamentarismo moderno, ver J. Heinck, Weimarer Staatslehre und Nationalsozialismus (1978), 30-35; H. Hofmann, Legitimität gegen Legalität (1964), 94; K. Sontheimer, Antidemokratisches Denken in der Weimarer Republik (1962), 331.

${ }^{47}$ Ver V. Neumann, 87ss.

${ }^{48}$ C. Schmitt, Völkerrechtliche Großraumordnung mit Interventionsverbot für raumfremde Mächte: Ein Beitrag zum Reichsbegriff im Völkerrecht (3 Ed., 1941); Der Nomos der Erde im Völkerrecht des Jus Publicum Europaeum (1950).

${ }^{49}$ Las conferencias y discusiones de esta conferencia, organizada del 1 al 3 de Octubre de 1986, en el Hochschule für Verwaltungswissenschaften en Speyer, están contenidas en Complexio Oppositorum (ver nota 4). 
ella, Schmitt fue interpretado, reconstruido, comparado, categorizado, justificado; los detalles de su biografía fueron estudiados minuciosamente, y su recepción (desde Italia hasta Corea) fue descrita en gran detalle. La impresión sobre Schmitt que dejó la conferencia fue la de alguien que, como persona, fascina a sus lectores y despierta controversias, pero que no logra el mismo efecto como un pensador cuyas teorías gozan de gran vigencia y se prestan para mayor desarrollo e implementación.

Hoy en día los lemas de Schmitt ya no funcionan como versiones abreviadas de sus teorías. Fascinan por sí mismos. Están soberbiamente formulados; y, sin embargo, el resplandor tan alabado del lenguaje de Schmitt no es el producto de un discurso excepcionalmente claro o bello, sino de una escogencia de palabras firme, definida, denodada. Ella entra marchando, no permite refutación alguna, no requiere ninguna justificación. No confronta otras posiciones como aspectos diversos de un argumento en desarrollo, sino que las usa como mera decoración. Nunca hay ambigüedad. Los seres humanos son por naturaleza buenos o malos; ${ }^{50}$ si una teoría política supone que son malos, entonces la teoría es cierta, pero si la teoría supone que son buenos, no lo es; el criterio político es el de amigo o enemigo; o una nación es capaz de tomar una decisión amigo-enemigo y así justifica su existencia política, o no es capaz de hacerlo, y por lo tanto carece de justificación; la legitimación sustancial se opone a la legalidad insustancial; la época de los Estados termina donde la era de las super-regiones y de los hemisferios comienza; y así continúa la serie de contrastes de Schmitt.

Este es el decisionismo como un estilo intelectual, y es el estilo el que produce la fascinación. Como una guía para la política, el decisionismo es, claramente, de un valor limitado. Desde luego que existen situaciones que exigen la toma de decisiones; pero otras situaciones sólo se superan soportando las tensiones, no disolviéndolas. Como un fundamento teórico para el derecho, el decisionismo tampoco es adecuado. La apoteosis de la decisión como el punto de partida de todas las normas legales puede tal vez ocultar,

\footnotetext{
${ }^{50}$ Desde luego, Schmitt no emplea esto en "un sentido moral o ético específico," sino como la diferencia entre "los conceptos problemático y no problemático del hombre.” Él señala como una "pregunta abierta" la relación entre su punto de vista y la idea del hombre de Helmut Plessner. Ver R. Kramme, Helmut Plessner and Carl Schmitt: Eine historische Fallstudie zum Verhältnis von Anthropologie und Politik in der deutschen Philosophie des 20. Jahrhunderts (1989). Sin embargo, esto no cambia la clara oposición, y el hombre de Plessner es, al menos para Schmitt, "más cercano al 'mal' [...] que al bien." Ver The Concept of the Political, 60.
} 
pero ciertamente nunca llenar, la brecha entre el ser y el deber ser. Los méritos del decisionismo como un estilo intelectual se encuentran en otro nivel. Los argumentos complejos se reducen a contrastes sencillos; las conjeturas y las refutaciones son dejadas de lado en nombre de la decisión; nuestro lugar en el tiempo y en la historia se resume en conceptos simples y claros. Afirmar que esto no funciona, y que es tan sólo una ilusión, es algo correcto como crítica. Pero desconoce el asunto de fondo; la ilusión puede orientar tanto como lo hace la realidad, y la orientación es precisamente de lo que se trata el decisionismo como estilo intelectual.

¿Por qué Carl Schmitt? Esta pregunta conduce entonces a otra: por qué la actual cultura jurídica de la República Federal de Alemania muestra tanto interés en el decisionismo de Schmitt a pesar de sus fallas, por qué existe tanta fascinación por el decisionismo como un estilo intelectual, y hasta se lo desea. La respuesta ha de hallarse en el desarrollo de la cultura jurídica durante los últimos cuarenta años.

\section{III}

La cultura jurídica de la República Federal de Alemania surgió de un doble rechazo. Por un lado, la definición positivista del derecho, que lo restringe al derecho positivo, fue censurada por la complacencia con que los abogados en el Tercer Reich enseñaron, discutieron, y administraron el derecho según las orientaciones nazis, sin protestar. ${ }^{51}$ Por otro lado, se repudió el decisionismo, también considerado responsable de la forma en que se abandonó la justicia bajo el régimen nazi. El concepto de la decisión amigo-enemigo como requisito de la existencia política fue percibido como una herramienta para que los nazis justificaran sus declaraciones de enemigo, con todas las injusticias que las acompañaron. ${ }^{52}$ Se difundió la idea de que el positivismo de Kelsen y el decisionismo de Schmitt eran intrínsecamente iguales: ambos se caracterizaban por ser formales e instrumentalizables, por carecer de contenido, de sustancia, y de un compromiso positivo con valores.

\footnotetext{
${ }^{51}$ Fue Gustav Radbruch quien formuló esta idea de la manera más clara. En su artículo "Gesetzliches Unrecht und übergesetzliches Recht, Süddeutsche Juristenzeitung” (1946), 105, Radbruch se apartó de su posición positivista, presentada en Rechtsphilosophie (3 Ed., 1932), 76ss.

${ }^{52}$ Fangmann, "Die Restauration der herrschenden Staatsrechtswissenschaft nach 1945," Das Recht des Unrechtsstaates: Arbeitsrecht und Staatsrechtswissenschaften im Faschismus (U. Reifner, 1981), 233ss.

${ }^{53}$ R. Graner, Die Staatsrechtslehre in der politischen Auseinandersetzung der Weimarer Republik (1980), 52ss, 79ss; H. Hofmann, 44ss.
} 
Al distanciarse del positivismo y del decisionismo, se trataba de restablecer un concepto de derecho correcto y justo, de derecho necesariamente adherido a los principios de justicia. El resultado fue el renacimiento del derecho natural en la década de los cincuenta. ${ }^{54}$ Esto tuvo un impacto no sólo entre los académicos del derecho, sino, además, en la práctica del derecho. En varias sentencias, el tribunal federal penal y civil usó el derecho natural explícitamente como medida. ${ }^{55}$ El tribunal constitucional federal se preocupó por no ser demasiado explícito en este aspecto, pero su manera de entender los derechos básicos como valores que componen un sistema de valores y de entender la acción libre como más o menos cargada de valor ${ }^{56}$ se fundamentó, de todas formas, en el renacimiento del derecho natural, propio de aquella época. Esta concepción sobrevive en la manera actual de entender los derechos básicos como principios. ${ }^{57}$ También sustenta la perspectiva actual de que los derechos básicos son elementos de un orden objetivo, ${ }^{58}$ con lo que se quiere decir que no son solamente derechos subjetivos individuales, sino que obligan objetivamente al gobierno a asegurar condiciones de libertad e igualdad.

La teoría constitucional que acompañó estos desarrollos fue la de Smend. De nuevo, el tribunal constitucional federal evitó cautelosamente las referencias expresas a ella. Sin embargo, su presunción de que los derechos básicos constituyen un sistema de valores encontró una evidente segunda fuente en el concepto de Smend de un sistema de valores de los derechos básicos como un sistema nacional de valores morales y bienes culturales. ${ }^{59}$ Para Smend, y para el tribunal constitucional federal en las décadas de los cincuenta y de los sesenta, predominaba el énfasis en la integración, en la conciliación en vez

\footnotetext{
${ }^{54}$ Naturrecht oder Rechtspositivismus? (W. Maihofer, 1962); H. D. Schelauske, Naturrechtsdiskussion in Deutschland: Ein Überblick über zwei Jahrzehnte, 1945-1965 (1968), 13; H. Welzel, Naturrecht und materielle Gerechtigkeit (1962), 219ss.

${ }^{55}$ BGHSt, GrS 6 en 46, 52ss; BGHSt 6 en 147, 153ss; BGHZ 9, en 34, 44; BGHZ 11 en app. 34, 49ss, 64; BGHZ 16 en 350, 353ss; ver G. Müller, Naturrecht und Grundgesetz: Zur Rechtsprechung der Gerichte, besonders des Bundesverfassungsgerichts (1967); Weinkauff, "Der Naturrechtsgedanke in der Rechtsprechung des Bundesgerichtshofs, Neue Juristische Wochenschrift” (1960), 1691.

${ }^{56}$ Ver B. Schlink, Abwägung, 17ss.

${ }^{57}$ Ver R. Alexy, Grundrecht, 125ss.

${ }^{58}$ Ver BVerfGE 59, 295/320; BverfGE 73, 261/269; BverfGE 74, 297/323; ver también K. Hesse, Grundzüge, 118ss; Stern, Staatsrecht, 899ss.

${ }^{59}$ Smend, "Das Recht," 48ss; R. Smend, Verfassung, 163.
} 
del conflicto, en la armonía entre el Estado y la sociedad, en la cooperación entre la empresa y el trabajo, en la coordinación entre el Estado y la Iglesia, y en un pluralismo consentido entre todos los grupos e intereses. ${ }^{60}$

Pero el rechazo del positivismo y del decisionismo, con el que empezó la cultura jurídica de la posguerra, nació de un mito. No fue el positivismo el que hizo que los abogados del Tercer Reich enseñaran, discutieran, y administraran el derecho según las orientaciones nazis; lo que llevó a ese resultado fue, en cambio, la fundamentación y penetración nazi del derecho, en ese momento recientemente propagada y aceptada. Los nazis habían rechazado el positivismo como algo demasiado formal y demasiado liberal mucho antes del renacimiento del derecho natural. ${ }^{61}$ De hecho, el positivismo no es simplemente la reducción del derecho al derecho positivo; también implica una construcción, racional y técnica, del sistema jurídico y de los derechos y deberes individuales. ${ }^{62}$ Esto limita la autoridad del Estado y brinda libertad individual.

Schmitt fue también un crítico del positivismo. Él ya lo había criticado durante la República de Weimar, ${ }^{63}$ pero lo hizo con especial vigor durante el Tercer Reich, en el contexto de su teoría de la sociedad sistemática y estructurada, su "konkretes Ordnungs und Gestaltungsdenken." ${ }^{64}$ Sin embargo, esto lo llevó a descartar no sólo el positivismo, sino también el decisionismo. Schmitt, junto con otros académicos juristas nazis, consideró que el decisionismo era insuficiente como una base y como un método para construir el sistema jurídico nazi. Ellos opinaron que el momento de decisión era demasiado breve para darle el debido reconocimiento a la legitimidad duradera del movimiento nazi. ${ }^{65}$ Así

${ }^{60}$ Ver P. Häberle, Öffentliches Interesse als juristisches Problem (1970), 716ss; Hesse, "Freie Kirche im demokratischen Gemeinwesen," en K. Hesse, Ausgewählte Schriften (P. Häberle y A. Hollerbach, 1984), 452; Scheuner, "Die Aufgabe der Gesetzgebung in unserer Zeit," en Wirtschaftliche und Öffentliche Verwaltung (R. K. J. Badenhopp, 1961), 30ss.

${ }^{61}$ Huber, "Einheit der Staatsgewalt," Deutsche Juristen-Zeitung (1934), 958; K. Larenz, ÜberGegenstand und Methode des völkischen Rechtsdenkens (1938), 10-11; F. Schaffstein, Politische Strafrechtswissenschaft (1934), 7; Schönfeld, "Der Traum des positiven Rechts," en 15 Archiv für die civilistische Praxis (1932), 1.

${ }^{62}$ Ver Fangmann, "Die Restauration," 219ss; I. Maus, Bürgerliche Rechtstheorie und Faschismus: Zur sozialen Funktion und aktuellen Wirkung der Theorie Carl Schmitts (2 Ed., 1980), 31ss; W. Rosenbaum, Naturrecht und positives Recht (1972), 151.

${ }^{63}$ Ya había hecho esto durante el reino del Kaiser. Ver la disertación de Schmitt, "Gesetz und Urteil" (1912).

${ }^{64}$ C. Schmitt, Über die drei Arten, 31ss, 66.

${ }^{65}$ Ibid., 24ss, 66. 
que, al intentar explicar el comportamiento de los operadores jurídicos durante el Tercer Reich, uno debe apuntar no al positivismo y al decisionismo, sino al rechazo del racionalismo, del formalismo y del relativismo en la jurisprudencia. El anhelo de una nueva base sustancial y de un nuevo desarrollo del derecho ya había empezado en la década de los veinte. ${ }^{66}$

El mito que se propagó en las décadas de los cincuenta y de los sesenta narraba una historia distinta, pero esto se debe a una variedad de razones. $\mathrm{Al}$ responsabilizar al positivismo y al decisionismo por la forma en que los abogados aceptaron el nazismo, el análisis jurídico sustancial, filosófico, histórico, e institucional que germinó durante el Tercer Reich podía abandonar sus connotaciones nazis y así continuar con su desarrollo. ${ }^{67}$ El hecho de que Kelsen no regresara a Alemania, y de que a Schmitt no se le permitiera seguir enseñando, llevó a que el positivismo y el decisionismo se convirtieran en cómodos chivos expiatorios. Como los estudios académicos en derecho después de 1949 fueron adelantados esencialmente por los mismos abogados que los habían realizado antes de 1945, fue grande una doble tendencia: primero, a continuar con los modos de pensar habituales, y, segundo, a demostrar de manera notoria el abismo que había aparecido al final del Tercer Reich.

En la década de los setenta, el mito dominante de los cincuenta y sesenta empezó a desvanecerse. Los motivos que lo impulsaban se debilitaron; el número de abogados que había enseñado, discutido, y administrado el derecho durante el Tercer Reich se desplomó. El positivismo y el decisionismo podían ser, nuevamente, objeto de investigaciones imparciales. Durante la década de los setenta también aumentó el interés histórico en el Tercer Reich. En parte, este interés se benefició por el hecho de que los académicos del derecho, que habían iniciado y adelantado sus carreras durante el Tercer Reich, llegaron a la edad de retiro. Cada vez más, historiadores, científicos sociales, y juristas

\footnotetext{
${ }^{66}$ Ver Heller, "Bemerkungen zur staats-und rechtstheoretischen Problematik der Gegenwart," en 16 Archiv für Öffentliches Recht (1929), 344; Kaufmann, "Die Gleichheit vor dem Gesetz im Sinne des Artikel 109 der Reichsverfassung," en 3 Veröffentlichungen der Vereinigung der Deutschen Staatsrechtslehrer (1927), 20; Leeb, "Grundfragen," en "Deutsche Richterzeitung" 1920, col. 52; Stoll, "Die nationale Revolution und das bürgerliche Recht," Deutsche Juristen-Zeitung 1933, col. 1229.

${ }^{67}$ Ver K. Larenz, Methodenlehre (1960), 363; H. v. Mangoldt y F. Klein, 1 Das Bonner Grundgesetz (2 Ed., 1966); Scheuner, "Die institutionellen Garantien des Grundgesetzes," en 4 Recht, Staat, Wirtschaft (H. Wandersleb, 1953), 88.
} 
jóvenes podían tratar el tema del Tercer Reich sin entrar en conflicto directo con sus profesores y sin arriesgar sus futuros profesionales. Esta combinación (el desvanecimiento del mito decisionista/positivista y el interés creciente en el Tercer Reich) despertaron un renovado interés por Schmitt. Él era aún más interesante y atractivo no sólo porque todavía estaba vivo, sino también porque era el centro de algo misterioso, una reverencia y algo así como un culto de seguidores.

El aumento del interés por Schmitt en la década de los setenta tuvo, incluso, otra causa. Los setenta ya no fueron años de integración y armonía. Desde 1968, el conflicto brotó en las universidades y en los colegios. Desde 1974, una economía en declive endureció la competencia y la lucha por la distribución de la seguridad social. En las disputas sobre la admisión de los llamados radicales a la función pública, una nueva forma de pensamiento amigo-enemigo apareció en la política nacional. Más adelante, la disputa sobre el rearme estropeó la ilusión de un consenso total entre los intereses alemanes y los intereses aliados, y las primeras fases del proceso de unificación alemana la lesionaron de nuevo. Todo esto no sólo despertó interés en una teoría constitucional que le prestara mucha atención a las crisis y a los fenómenos patológicos en el Estado y en la sociedad; además, exigió, y continuó exigiendo, toma de decisiones. Estas decisiones no necesitaban encajar en las categorías amigo-enemigo, y podían tomarse en apoyo de la idea de soportar las tensiones. Pero son decisiones, y no automatismos integradores y armónicos. Entre más complicados se tornan el mundo, y las decisiones que debemos tomar sobre quiénes somos, cuál es nuestra posición, y en qué nos queremos transformar, más fuerte se hace el anhelo por decisiones tajantes; así se explica la atracción del decisionismo como un estilo intelectual.

\section{IV}

¿Por qué Carl Schmitt? La respuesta es todavía incompleta. El interés actual por Schmitt no se concentra en su obra como tal, sino más bien en Schmitt como persona, en su desarrollo, sus transiciones, y sus roles; la magnitud de esta concentración revela otro aspecto del valor de Schmitt para la cultura jurídica de la República Federal de Alemania. Éste es, a mi juicio, el punto más importante. A través de Schmitt, nuestra cultura jurídica ha luchado, y continúa luchando, para reconocer y admitir al Tercer Reich como parte de su historia.

Este desarrollo sigue a décadas de represión. La represión le permitió al mito decisionista/positivista forjar la ilusión de un inicio completamente 
nuevo luego del final del Tercer Reich. El mito ocultó la continuidad de las personas, los temas, y las teorías. La represión también hizo que los problemas constitucionales firmemente asentados pudieran ser tratados como si estuvieran surgiendo por primera vez al inicio de la década de los cincuenta. La represión se mostró de manera notoria en la práctica de encerrar la literatura legal del Tercer Reich en secciones separadas de las bibliotecas, en los llamados "cajones venenosos."

La represión no sólo surgió por el deseo de proteger a quienes habían estado envueltos en el Tercer Reich. Otra causa, probablemente mucho más importante, consistía en la dificultad de integrar el pensamiento jurídico nazi en la historia de la cultura legal alemana. El pensamiento legal nazi nada tenía que aportarle a esta cultura. No había producido nada duradero, nada que mostrara independencia intelectual, nada que mereciera un discurso intelectual. Únicamente un estorbo. Dentro de su banalidad, ${ }^{68}$ el mal no podía generar nada distinto a banalidades intelectuales. Y así como el mal, por su banalidad, es difícil de integrar en la historia nacional, del mismo modo es difícil encontrarles cabida a sus productos intelectuales.

Pero el período de 1933 a 1945 no se puede borrar de la historia de Alemania. La integración es una tarea inevitable, de la que no es posible escapar. Y esta tarea parece ser más fácil con Schmitt. Al considerar su obediencia al nazismo y su celebración de Hitler después de 1933, su justificación del crimen nazi, su actividad en contra de los académicos jurídicos judíos, que llegó hasta el acoso ${ }^{69} \mathrm{Schmitt}$ parece ser de la misma banalidad del mal que todos los demás. ¿Pero qué pasa cuando se le observa de nuevo? ¿No es de esperarse que alguien de la talla intelectual y de la gran inteligencia de Schmitt signifique algo más, signifique algo distinto, algo diferente y más profundo de lo que leemos en la superficie? ¿Habrá acosado tal vez a los académicos jurídicos judíos no como un antisemita sino como un antijudaízante? iSerá que no trató simplemente de fortalecer al nazismo intelectualmente, sino más bien de sujetarlo a una estructura y a una tradición intelectuales, con miras a disciplinarlo? Después

${ }^{68} \mathrm{H}$. Arendt, Eichmann in Jerusalem: A Report on the Banality of Evil (Viking, 1963).

${ }^{69}$ En especial, ver Schmitt, "Der Führer schützt das Recht: Zur Reichstagsrede Adolf Hitlers vom 13, Juli 1934," Deutsche Juristen-Zeitung 1934, col. 954; Schmitt, "Die Verfassung der Freiheit," Deutsche Juristen-Zeitung 1935, col. 1133; Schmitt, "Die deutsche Rechtswissenschaft im Kampf gegen den jüdischen Geist: Schlußwort auf der Tagung der Reichsgruppe Hochschullehrer des NSRB vom. 3.-4. Oktober 1936," Deutsche Juristen-Zeitung 1936, col. 1193. 
del crimen de 1934 [el 30 de junio, la Noche de los cuchillos largos], ihabrá exaltado al Führer como protector de la ley sólo para hacerlo responsable por lo que hizo y por lo que debería suceder? ¿No será el suyo el destino trágico del intelectual que intentó una gran tarea pero que fracasó? Y, sin embargo, aún si Schmitt de hecho no significó nada diferente y más profundo en 1933 de lo que leemos en la superficie, ¿no yace ahí la verdadera tragedia? ¿No es la tragedia del intelectual que, por la misma claridad de su visión, está condenado a vivir sin hogar y a la vez a añorar una Heimat, añorar ser parte de algo, pertenecer a algo, entregándose así al mythos Nazi de la comunidad étnica? Incluso si Schmitt hubiera sido tan sólo un oportunista, sólo interesado en su carrera después de 1933, iacaso aun así su oportunismo no habría tenido cierto carácter trágico? La venta de la primogenitura intelectual sólo por un plato de lentejas: un puesto como Staatsrat [consejero de Estado] prusiano. Si esto no es trágico, ¿no es, al menos, irónico?

Estas preguntas no son mías. En mi opinión, ni siquiera son preguntas apropiadas. Son el producto de la forma en que Schmitt se presentó a sí mismo durante su vida, especialmente después de 1945, con magistral habilidad. Pero estas preguntas aparecen cada vez que el tema es Schmitt. Esto muestra que Schmitt es valioso para la cultura jurídica de la República Federal de Alemania no a pesar de su rol en el Tercer Reich, sino a causa de ese rol. Su rol puede haber sido moralmente lamentable y profundamente fracasado, pero al menos no aparece como algo banal. En la forma en que lo interpretó un hombre de esa talla intelectual y gran inteligencia, el rol del abogado en el Tercer Reich puede parecer fascinante, enigmático, inclusive trágico. Y eso ayuda a integrar el capítulo del Tercer Reich en la historia de la cultura jurídica alemana. Esto no es necesariamente un esfuerzo por purificar el Tercer Reich. Tampoco se trata de estar en contra o a favor de Schmitt. Surge del deseo compartido de ver en el mal no sólo la banalidad, sino el esfuerzo fallido. Aún en el enemigo uno busca más que la mera banalidad del mal. Para decirlo de una forma algo melodramática: no basta con que Satanás sea Satanás; debe ser un ángel caído.

Pero la labor de integrar el período de 1933 a 1945 en la historia alemana no es un asunto de demonios, enigmas, mito, o tragedia. No se puede lograr presentando a Schmitt como una figura que, trágicamente amarrada, fracasó; tampoco se puede lograr atribuyéndoles a la teoría y a la práctica jurídicas de esos años un brillo trágico. La tarea consiste en admitir y soportar el mal en su banalidad, y asimismo en reconocer la banalidad de sus expresiones intelectuales. Ese período ha de ser integrado en la historia según este modo de comprenderlo. Si esto se hace con éxito, Schmitt regresará a las filas de 
los académicos constitucionales y de los teóricos de la política de su época. Entonces la Goethe House y la New School no organizarán una conferencia sobre Schmitt, el individuo, sino sobre los problemas que él y muchos otros trataron y que él ni creó ni solucionó. Entonces se le negará la estatura de clásico que sus defensores intentan asegurarle. ${ }^{70}$ Ellos triunfarán en este esfuerzo sólo si nosotros nos permitimos llegar a ser cómplices en el esfuerzo común de negar la banalidad del mal.

${ }^{70}$ Ver Quaritsch, "Einleitung: Über den Umgang mit Person und Werk Carl Schmitts," en Complexio Oppositorum, 13; Willms, "Carl Schmitt - Jüngster Klassiker des politischen Denkens?," Ibid., 577. 
